\title{
ALTERNANCIA DE CÓDIGOS Y EMOTIVIDAD. A PROPÓSITO DEL CONTACTO LINGÜÍSTICO CATALÁN-ESPAÑOL
}

\author{
M. Victoria Mateo García \\ Universidad de Almería \\ Francisco García Marcos \\ Universidad de Almería \\ http://dx.doi.org/10.18778/8220-201-4.19
}

\section{Resumen}

El presente trabajo analiza la alternancia de códigos entre catalán y español, a partir de un muestreo empírico de 2’37 horas. En ese corpus se pone de manifiesto que, junto a los factores tradicionales que explican la aparición de ese fenómeno, influye de manera significativa, al menos en algunas ocasiones, la emotividad asociada al uso de las lenguas y a las relaciones interpersonales.

Palabras clave: Alternancia de códigos, emotividad, lenguas en contacto.

La alternancia de códigos ha sido una de las constantes clásicas en la aproximación sociolingüística a las situaciones de lenguas en contacto. Desde el principio no ha tenido mayores problemas en cuanto a su delimitación nocional, toda vez que se ha ocupado de la utilización variable de dos códigos verbales dentro de un mismo evento comunicativo. Esa definición estándar, ya de por sí amplia, está en condiciones de hacer frente a una casuística prolija. En principio y en teoría, también podría registrarse code-switching cuando se alternaran dos dialectos, o dos variedades, de una misma lengua. 
Sin embargo, los especialistas han primado el examen del contacto lingüístico. Ese ámbito, de todas formas, ha bastado para generar una más que considerable producción empírica y teórica. Como recordaban Appel y Muysken (1989: 175-178), esas investigaciones han cubierto desde incidencia interlingüística puntuales hasta textos relativamente complejos y elaborados.

Por lo demás, parece que no se trata de un fenómeno relativamente reciente, derivado de dinámicas sociolingüísticas contemporáneas, sino que vendría a ser una constante, más o menos universal, más o menos consustancial, al contacto lingüístico en sí. Desde luego, está documentado desde antiguo. Burke (1993: 77) refiere el caso de las Cartas de sobremesa de Lutero, en latín o en alemán según la mayor/menor gravedad y solemnidad del tema. No cuesta tampoco demasiado suponer situaciones análogas, a expensas de los datos que pudiera arrojar la investigación monográfica y detallada al respecto. Pero, en principio y en modo hipotético, cabría suponer la posible existencia de algún modo de code-sitwching entre las legiones romanas, en la corte de Kublai Kan o, por no excederse en los ejemplos, entre los sefarditas establecidos en el Imperio Otomano.

Appel y Muysken (1987: 175) proponen situar la alternancia de códigos en unas coordenadas tridimensionales determinadas por otros tantos ejes fundamentales de condicionamientos:

1. Sociolingüístico, desde el que se desarrollarían las condiciones contextuales que hacen posible el intercambio de códigos.

2. Psicolingüístico, responsable de los mecanismos individuales que articulan una competencia lingüística capaz de interactuar intercambiando dos códigos distintos.

3. Lingüístico, mediante el que se discriminarían las fronteras entre esta y otras consecuencias del contacto entre lenguas, caso de la transferencia o de la interferencia.

Se trata, desde luego, de una propuesta de taxonomía razonable, aunque no por ello deje de ser matizable y, en todo caso, haya sido matizada de facto. La bibliografía, en realidad, se ha desentendido del componente psicolingüístico, siempre de difícil y delicada mesura empírica. De manera que en la práctica se ha concentrado la atención en los dos restantes. 
El componente lingüístico, y su correspondiente caracterización, quedaron considerablemente fijados a partir de las investigaciones neoyorkinas de S. Poplack (1980). De modo sintético, la alternancia de códigos se produce desde posiciones muy concretas del sistema lingüístico:

1. Las estructuras superficiales de dos lenguas.

2. Los cambios de código se activan en morfemas independientes.

3. Debe registrarse equivalencia estructural, co-gramaticalidad, entre las dos lenguas implicadas en el punto en el que se registra el cambio de códigos.

4. El tipo de competencia de los hablantes condiciona los intercambios, lo que a su vez produce un gradatum de code-switching, iniciándose en los cambios de etiquetas, continuando en los cambios oracionales, para culminar en los intra-oracionales.

A ese primer listado, la bibliografía fue añadiendo nuevas especificaciones, en principio también universales, o tendencialmente universales. De esa manera, otros factores propiciadores del desarrollo de intercambios de código serían los siguientes:

5. La proximidad tipológica de las lenguas implicadas.

6. La codificación de citas o el discurso indirecto.

7. Las repeticiones con fines enfáticos.

8. La ubicación entre un núcleo nominal y una cláusula de relativo.

9. En las construcciones copulativas, su posición entre sujeto y predicado.

Desde el eje social también se aisló un número significativo de condicionamientos, preferentemente vinculados a la situación de comunicación y al sistema de marcas sociolingüísticas de cada comunidad. El cambio de código venía a ser una estrategia comunicativa, mediante la que se empleaba un indicador de pertenencia a un grupo, con la intención de llamar la atención de los interlocutores a través de la forma del mensaje. El entorno entre el que se desarrolla propicia -o inhibe- la aparición de cambios de código. Lo más favorable es un clima de intimidad comunicativa, mientras que en el extremo opuesto se situarían las situaciones de máxima formalidad comunicativa, abordadas mediante una sola lengua. En ese sentido, Blom y Gumperz (1972) establecieron una 
díada clásica que discriminaba entre cambios metafóricos (según los objetivos comunicativos) y cambios transaccionales (según la formalidad).

En todo caso, la bibliografía reconoce la dificultad de predecir sistemáticamente cuál va a ser la selección de una u otra lengua. La mayor incertidumbre parece concentrarse en torno al tópico en torno al que gire la comunicación. No existe una tipología unívoca de temáticas que propicien, o retraigan, la aparición de cambios de código. Sí ha habido intentos más claros por vincularlos a actos de habla muy específicos. En concreto, Fasold (1984: 23) discrimina tres: los mandatos, la legitimización de la veracidad de un punto de la narración y un uso enfático en la comunicación de los adultos con los niños. Por otra parte, es evidente que la realidad empírica ha desbordado ampliamente los márgenes propuestos por Fasold, como se trató de resumir en García Marcos $(1999,2015)$, según estuvieran vinculados a los componentes de la comunicación:

1. Participantes, como estrategia de acomodación al interlocutor o como negociación de la identidad frente a los demás.

2. Mensaje, como método para aclarar contenidos ya enunciados o como indicio del dominio de dos lenguas frente a otros interlocutores.

3. Estructura del discurso, empleado para regular el ritmo comunicativo en general, y en particular para marcar la apertura y clausura de los eventos, de un lado, y, de otro, el paso del estilo directo al indirecto.

4. Tema, asignando una lengua a un ámbito temático, dotándolo así de valor simbólico.

5. Canal, seleccionando una lengua para la transmisión de comunicación a través de un medio.

6. Expresión poética, en calidad de recurso mediante el cual enfatizar la adscripción a una identidad.

Con todo, la bibliografía ha ido dejando cabos sueltos a lo largo de todos estos años, datos que quedaban fuera de ese amplio marco general que acaba de comentarse. En una de las investigaciones pioneras, Lindholm y Padilla (1978) señalan que solo el $2 \%$ de los niños bilingües inglés/español en EE.UU. utilizan el 
cambio de código, dentro de una muestra de 500 encuestados. Por supuesto que ese comportamiento, muy marcado conforme a sus cifras, puede obedecer a múltiples factores, aunque todos ellos, no obstante, giran en torno a un proceso directamente asociado a la socialización del individuo; esto es, el cambio de código va intensificando su presencia a medida que los niños se convierten en adultos. Luego, no es una resultante directa del contacto lingüístico como tal, sino de algunos tipos de gestión social del mismo; aspecto este último que tampoco se ha indagado de manera pormenorizada.

Con el tiempo, la casuística alcanzó a prácticamente cualquier manifestación verbal. En sentido estricto, las nuevas lenguas incorporan cambios de código incluso en sus primeros registros escritos, cuando alternan la lengua fuente y sus derivaciones. Los patrones tradicionales, por momentos, parecieron desdibujarse, forzados a incluir nuevas perspectivas. Cuando en 1989 Biondi-Assali examina el caso de la comunidad árabe en Argentina, no encuentra mayores problemas para determinar sus contextos lingüísticos de aparición, limitados a los casos de morfema dependiente. Lo determinante para estos hablantes radicaba en el uso del cambio de código como expresión de rasgos étnicos de solidaridad. Ese valor tampoco era desconocido por la bibliografía, tal y como también se ha referido líneas más arriba. Lo realmente novedoso de la situación argentina que analiza Biondi-Assali es una preponderancia tan acusada de esa función, por encima de cualquier otra clase de condicionamientos. Eso podía suponer otra potencial pequeña grieta en el edificio conceptual del cambio de código.

La investigación que aquí presentamos no parte, en todo caso, de ninguno de esos puntos de disonancia en la conceptualización del cambio de código. Simplemente las tiene presentes, como evidencia de que la bibliografía ya había explorado otras posibilidades, más allá de las abrumadoramente mayoritarias en la bibliografía.

Desde esa perspectiva, se abordó un corpus, tomado en un contexto con un contacto lingüístico tan prolongado e intenso como el protagonizado por el español y el catalán. En sentido estricto, el catalán ha vivido muy poco tiempo sin estar en contacto con alguna 
otra lengua, lo que ha convertido al contacto en una de sus constantes sociolingüísticas históricas. En ese contexto se examina una muestra de 2,37 horas de grabaciones recogidas en el área metropolitana de Barcelona entre diciembre y marzo de 2014. Todas ellas son interacciones cotidianas y reales, en las que abundan los cambios de código. De todas las interacciones muestreadas, un 20,8\% de ellas acudieron a ese recurso. Es complicado estimar la relevancia última de ese dato cuantitativo, ya que no hay parámetros de referencia estadísticas claros en función de los que valorar esa cifra. Por una parte, las interacciones verbales potenciales de una comunidad de habla son, por definición, indeterminadas. Por otra, tampoco existe una posible tipología temática asignada a una u otra situación comunicativa. Sí que, en todo caso, la muestra destaca algunos aspectos cualitativos bastante relevantes.

Por supuesto que todos los hablantes implicados son bilingües. Solo que esa competencia puede desarrollarse en interacciones monolingües, con predominio absoluto de catalán o de español, o en interacciones bilingües, en las que se empleen las dos lenguas, bien entre dos interlocutores, bien entre varios de los participantes en una conversación más amplia. Estas últimas, naturalmente, aportan el mayor número de casos de alternancia de código. Entre hablantes de español no aparecen alternancias de código en catalán, al menos en la muestra que se analiza aquí. Por supuesto que hay transferencias, calcos e interferencias abundantes entre las dos lenguas, como recoge el ejemplo siguiente.

L1 - ¿Has estado, M., en la plaza?

L2 - Sí, pero al final me he vuelto sin comprar fruta.

L1 - ¿Nada?

L2 - Es que TAMPOCO NO he visto nada en condiciones, $A$.

L1 - Pues el otro día había unos plátanos canarios buenísimos. Ynaranjas.

L2 - Pues no te digo que no. Será que iba buscando POMAS y no me ha convencido lo que he visto.

"Pomas" es un catalanismo que sustituye a "manzanas" y la doble negación del "tampoco no" es ajena al español, pero propia del catalán. 
El siguiente ejemplo sí recoge alternancia en una conversación monolingüe en catalán:

L1 - No estic pas disposat a fer cap mena de concessió. Que ho tingui ben clar.

L2 - Vaja, t'has posat en plan EL FEO, EL DURO Y EL MALO.

L1 - No, no, no, res de FEO DURO YMALO. Es que no es pot badar amb aquestes coses, eh! Es molt seriós tot això.

El ejemplo muestra una muy significativa asimetría sociolingüística de fondo. El catalán, dentro de la diglosia, ha ocupado históricamente el estatus de lengua B. Por tanto, se muestra más propicia a este tipo de intercambios, entre otras cosas porque muy probablemente tiene que manejar referentes sociales que solo han circulado en la Lengua-A, es decir, en español. De hecho, no hubo doblaje en catalán de la famosa película de Sergio Leone, sobre la que los hablantes hacen una versión enfática, de "El bueno, el feo y el malo" a "El feo, el duro y el malo".

El ejemplo siguiente procede de un evento con alternancia coordinada de código:

L1 - $(\rightarrow L 2)$ Ens anem, que demà tenim feina $(\rightarrow L 3)$ M., vamos, recoge, que nos vamos ya.

L2 - $\rightarrow$ L1) Que no agafeu el túnels?

L1 - $\rightarrow L 2)$ Clar, sempre. Es que si no triguem massa. $(\rightarrow L 4)$ ¿Y tú, has terminado ya?

L2 - Doncs em sembla que es [...]

$L 4$ - $(\rightarrow L 2)$ Mare, no siguis pesada $\rightarrow L 1)$ Yo estoy desde antes de venir: he venido por dar un paseo.

L3 - $\rightarrow L 4)$ Que 'm puc emportar això? Es que me lo quiero llevar a casa, papá.

$\mathrm{L} 4$ - $(\rightarrow \mathrm{L} 3)$ Mare meva, ens tindrem que sortir de casa. Pues pregúntale a tu abuelo.

L5 - [risas] $(\rightarrow L 3, L 4)$ Ya está preguntado y respondido. Llévate lo que quieras, hija.

L6 - ( $\rightarrow$ L6) Demà al matítens lo del carrer de La Palla. No t'oblidis, $X$.

L4 - ( $\rightarrow$ L6) Quins collons, un parvulet! Tenen l'estudi des de divendres passat, pare. 
L1 - Bueno, ¿vamos estando? ( $\rightarrow$ L6) No te preocupes, P., ya se lo recuerdo yo.

L6 - $\rightarrow$ L1) Mejor. Más tranquilo me quedo.

$L 4-(\rightarrow L 7)$ Tiene cojones esto! $(\rightarrow L 2)$ Que te fallat alguna vegada?

$\mathrm{L} 7-(\rightarrow \mathrm{L} 4)$ Es que tiene ganas de oírte [risas].

L6 - $\rightarrow\llcorner 4)$ Mai, però perquè abans t'emprenyo una mica [risas].

$\rightarrow L 1)$ Estoy pensando que me voy a ir con vosotros.

L2 - $(\rightarrow$ L6) Un altre!, Quina presa tens? $(\rightarrow L 7)$ Quina gen, sempre amb presa.

L6 - $\rightarrow$ L2) Aixíno vaig sol, que ja saps que no m'agrada.

$\mathrm{L} 7$ - $(\rightarrow \mathrm{L} 2)$ Bueno, mujer, ya vendrán días y ollas.

Todos los hablantes son bilingües (pasivos como mínimo), recurriendo a las dos lenguas conforme van interviniendo los hablantes, susceptibles de encuadrarse en dos grandes clases:

1. Los sistemáticamente monolingües. Estos siempre se dirigen a los demás en su lengua materna (no en la lengua del receptor), caso de L2, L5 y L7.

2. Los hablantes que alternan catalán y español. Se trataría, por una parte, de L3 y L4 que lo hacen asociado a temáticas que evocan a otros hablantes. Y, por otra parte, L1 y L5 en los que se asocia a su particular relación interpersonal con algunos participantes, incluso por encima de lo que parecen ser normas familiares internas.

Por tanto, las actuaciones de L1, L3, L4 y L5 están claramente regidas por componentes emotivos. El caso siguiente introduce variantes de relación personal y singularizada entre los hablantes:

L1 (>L2) Es que estas cosas me EMPREÑAN, tú ¿qué quieres que te diga?

L2 (>L1) O sea, que te has vuelto independentista.

L1 (>L2) Mira que te gusta oírme. Yo moriré maño.

L2 (>L1) Entonces, ¿a qué viene el cabreo?

L1 (>L2) Coño, a que empiezan con que hay que mandar los tanques a Cataluña, porque aquí se va persiguiendo a la gente y no sé cuántas barbaridades más están diciendo. ¿Tú estás viendo algo de eso? ¿Tú de verdad crees que los que vivimos aquí nos merecemos eso? 
L2 (>L1) Pues yo si me he vuelto independentista

L1 (>L2) Ya, seguro. El primero de todos.

L2 (>L1) A ver si echan al Barça de la Liga

L1 (>L2) Ja t'agradaria a tu. LO QUE pasa es que no sabeu com fer-ho. Som l'equip de Barcelona, de Catalunya y del Mon. $Y$ vosaltres piu, piu, piu

L2 (>L1) No entiendo nada de catalán

L1 (>L2) Ja et fotarán, ja.

L3 (>L1, L2) Mira que llegáis a ser fanáticos los futboleros!

L1 (>L3) Es que el Barça es un club grande, conocido en el mundo entero y a estos no lo pueden entender. Empiezan en Cornellá y terminan en El Prat.

L2 (>L1) Ofendiendo como siempre, made in Farsa.

L1 (>L3) Yencima les cuesta reconocer las cosas

L3 (>L1, L2) Un par de pelmazos, eso es lo que sois.

Como en el caso anterior, y como en general en la inmensa mayoría de la muestra, todos los participantes son bilingües. En esta ocasión, como inmigrantes de segunda generación, el grueso del evento comunicativo se desarrolla en español, lengua vehicular entre los tres participantes. Se registra tan solo una alternancia de código cuando interviene L1, exclusivamente al dirigirse a L2, hablando de fútbol y refiriéndose de manera explícita al F. C. Barcelona. La suma de los tres factores es necesaria para que se genere esa alternancia en catalán. Cuando aborda la misma temática (el fútbol y el Barcelona) con L3, sin embargo, lo hace en español. Por lo demás, L1 es el hablante más permeable a las interferencias entre ambas lenguas ("empreñar" en español, por "enfadar", o "cabrear"; "lo que..." en catalán, en lugar del normativo "el que.....")

El siguiente ejemplo muestra una interacción muy rápida, sintomática también de hasta qué punto los primeros contactos lingüísticos condicionan el resto de la interrelación idiomática de los individuos:

L1 (>L2) Tot enllestit. Cap problema

L2 (>L1) Com digueu. Jo puc agafar també un taxi, eh? 
L1 (>L2) No, no cal. Hi halloc per a tothom. No pateixis. Tu te'n vas amb el P. I jo m'emporto al F. i al J.

L2 (>L1) Bé, perfecte

L2 (>L3) P., me voy contigo. Cuando tú digas.

L3 (>L2) Estupendo. Pues ya.... Si no hay que llevarse a nadie más, no sé

L2 (>L3) Yo tampoco. Es A. quien lo está organizando todo. Yo ando perdido, tú.

L3 (>L1) Escolta, A., que tinc que portar mes gent?

L1 (>L3) No, no. Està bé. Marxeu quan vulgueu. Ens veiem al Mistinguet.

L3 (>L1) Molt bé. Doncs, no sé, ara mateix?

L1 (>L3) Si, clar, quan vulgueu, quan vulgueu.

El evento discurre, casi por completo, en catalán. Solo se alterna con el español cuando interactúan L2 y L3 entre sí, lo que denota que la relación idiomática entre ambos discurre necesariamente en español, aunque se desarrolle en un contexto monolingüe. Es, por lo tanto, un rasgo que obedece única y exclusivamente a su relación interpersonal.

Es evidente que, al menos a tenor de lo visto en los ejemplos que acaban de comentarse, una parte de la alternancia de códigos está regida por factores clara y exclusivamente emocionales, fuera de los parámetros entre los que hasta el momento ha trabajado la bibliografía sociolingüística. De manera que puede subrayarse con bastante fundamento la existencia de condicionamientos procedentes de la emotividad de los individuos que intervienen en un evento comunicativo en el que se alternan los códigos. Es de suponer que el caso catalán/español no sea un ejemplo aislado y ocasional, sino más bien el exponente de lo que podría ser una constante, imprevista hasta ahora, en ese tipo de relaciones dentro de las situaciones de contacto lingüístico.

\section{Referencias bibliográficas}

Appel, R. y P. Muysken (1989/1996), Bilingüismo y contacto de lenguas, Barcelona: Ariel. 
Biondi-Assali, E. (1989), “Alternancia de los códigos español-árabe entre los bilingües de Tucumán, Argentina”, Caravelle, 52, 33-55.

Blom, J. P., \& Gumperz J. (1972), "Social meaning in linguistic structure: Code-switching in Norway", en J. Gumperz, \& D. Hymes (eds.), Directions in sociolinguistics, New York: Holt, Rinehart and Winston, 407-434.

Burke, P. (1993), The Art of Conversation, Cornell: Cornell U. P.

Fasold, R. (1984), The Sociolinguistics of Society, Oxford: Blackwell. García Marcos, F. (1999), Fundamentos críticos de sociolingüística, Almería: UAL.

García Marcos, F. (2015), Sociolingüística, Madrid: Síntesis.

Lindholm, Kathryn J. y A. M. Padilla, A. M. (1978), "Language Mixing in Bilingual Children", Journal of Child Language, 5:2, 327-335.

Poplack, S. (1980), "Sometimes I'll Start a Sentence in Spanish y Termino en Español: Toward a Typology of Code-switching”, Linguistics, 18, 581-618. 